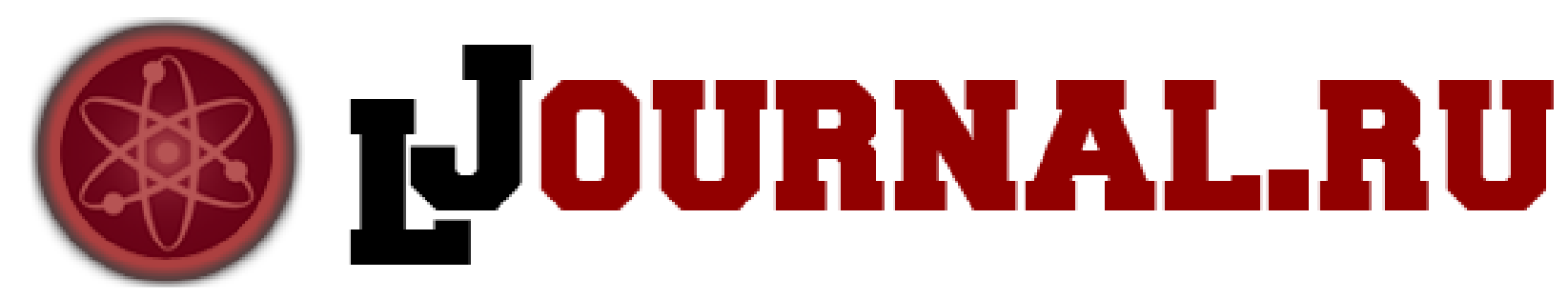

Коршунова О.А. Академия сочиального управления Москва, Россия

doi: 10.18411/1j2016-2-09

\title{
Прикладная направленность преподавания высшей математики
}

\section{«Математику уәс за то изучать следует, что она ум в порядок приводит" \\ М.В. Ломоносов}

Одним из важнейших аспектов преподавания математики является обучение студентов искусству математического моделирования, которое состоит в умении перевести прикладную задачу на математический язык, не теряя основных свойств оригинала. На основании опыта преподавания в академии разработана методика и последовательность изложения разделов высшей математики, теории вероятностей и математической статистики с построением и использованием математических моделей. Тем самым устанавливается взаимосвязь предмета с проблемами практики, что способствует повышению качества подготовки специалистов по профилям академии. Прикладной аспект преподавания состоит в нахождении связей предмета с практическими вопросами. При изложении для экономистов и менеджеров основ линейной алгебры, можно начать с рассмотрения систем линейных уравнений, как математических моделей различных экономико-технологических задач об организации производства, нахождении плана выпуска продукции в зависимости от использования ресурсов, задачи о товарообороте предприятия. 
Завершить материал целесообразно матричными моделями в финансах, бизнесе и коммерции, которые отображают соотношения между затратами на производство и его результатами или модели межотраслевого баланса.

С помощью векторов описываются различные математические понятия. Здесь можно выделить экономический смысл скалярного произведения, привести простейшие математические модели, использующие понятие вектора: запас, поступление и реализация запасов товаров на складе, доход от торговой деятельности предприятия, стоимость товарных остатков, готовой продукции, прогноз выпуска и т.п. При решении некоторых экономических задач часто характер взаимосвязей между основными показателями представляется прямыми линиями или кривыми второго порядка. Можно рассмотреть прямую как модель зависимости выработки от объема товарооборота, построить модель разделения рынка сбыта, чтобы расходы предприятия были наименьшими (окружность); параболу, как математическую модель зависимости финансовых накоплений от объема выпуска продукции.

Математические модели рассматриваются и при изучении функций, например, зависимость прибыли от издержек производства, стоимости от оптовых закупок, дохода от объема продаж, спроса от цены. Множество различных экономических ситуаций моделируется с помощью производной, интеграла, функции нескольких переменных: уровень рентабельности в зависимости от прибыли, основных и оборотных средств; зависимость объема производства от факторов производства; предельная производительность; эластичность объема производства относительно живого и овеществленного труда; эластичность при анализе спроса и предложения, спроса и цены; кривая предельных издержек производства; функция дохода, потребления, спроса; объем продукции; определение среднего времени затрат на изготовление продукции в зависимости от степени освоения производства; определение запасов товаров на складе; определение полных издержек производства. 
Интегральное исчисление связано с решением задач на вычисление площадей фигур, длин дуг кривых, поверхностей и объемов тел вращения.

В рамках линейного программирования можно смоделировать задачи об использования ресурсов; удовлетворении ассортиментного спроса потребителей; задачи о наиболее рациональных перевозках грузов; о размещении заказов и т.п.

Совокупность случайных фактов лежит в основе любого процесса массового обслуживания, телефонной связи, торговли, транспортных услуг, медицинской помощи. Например, решение практического вопроса: сколько нужно иметь дежурных врачей, чтобы им не приходилось долго бездействовать в ожидании вызова, а с другой стороны - больным не приходилось долго ждать помощи. Разработаны специальные теории, использующие фактор случайного: теория массового обслуживания, теория игр, теория случайного поиска.

Математические модели, рассматриваемые при изучении теории вероятностей и математической статистики, являются эффективным аппаратом при разработке психологических тестов, их анализе и составлении заключения, например, при отборе кандидатов на вакантную должность. Они позволяют выявить причины, мешающие общению в коллективе, группе. Чтобы получить эффективные результаты, необходимо собрать статистические данные по интересующей проблеме и обработать их, используя современные информационные технологии. Но информационные технологии - это инструмент в руках специалиста, который должен поставить задачу, выбрать метод исследования и уже для решения использовать нужную компьютерную программу. Умение применять математические методы и есть математическое моделирование. Преподавание математики, основываясь на прикладном аспекте, позволяет заинтересовать студентов, завладеть их вниманием и повысить качество образования. Слова великого русского ученого Михаила Васильевича Ломоносова должны быть лейтмотивом преподавания математики с первого класса начальной школы. Тогда отпадет вопрос: «Зачем мне математика, я гуманитарий?» Математика - наука всех наук. В изобразительном искусстве 
действует правило «золотого сечения»; в музыке - доли, такты. Математика это наука, любовь к которой надо прививать со школы, тогда в высшей школе легче будет найти общий язык со студентами при изучении профильных математических дисциплин. 